\title{
Contemplating Ocean Wave Measurements
}

\author{
Paul C. Liu \\ Great Lakes Environmental Research Laboratory, National Oceanic and Atmospheric Administration, Michigan, USA \\ Email: paul.c.liu@noaa.gov
}

Received October 31, 2012; revised November 29, 2012; accepted December 29, 2012

\begin{abstract}
This is a personal contemplation on the state of ocean wave measurement, historically, and with an eye toward the future. The conceptual basis which leads to the conventional wave measuring instruments has been in practice for over six decades which is basically single point observations of three-dimensional waves. We need new conceptual advancement and new instrumentation to rejuvenate our research in stagnation. New instruments for spatial wave measurement have been on the horizon.
\end{abstract}

Keywords: Ocean Waves; Single Point Wave Observations; Spatial Wave Measurements

\section{Introduction-Some Historical Reflections}

From all indications, the earliest starting usage of a wave gage for wave measurement-a single point underwater apparatus to measure pressure fluctuations under the wave surface, as Barber (1969) [1] proudly puts it some years ago: “... was made in Britain about 1945”. That was really the conceptual beginning of the modern wave measurement system made from a single-point location to represent the ocean wave processes.

But as Titov (1969) [2] pointed out that one of the first compilations of wind-wave measurements was made much earlier by the 18th century scientist Luigi Ferdinado Marsigli (1658-1730) around 1720's in Mediterranean waters. Indeed, in McConnell's (1986) [3] report on Marsigli's voyage to Landon and Holland, 1721-1722, which included Marsigli's long Letter to the Royal Society on his voyage that had included the Plate of Marsigli's hand drawn wave observations as shown in Figures $\mathbf{1}$ and $\mathbf{2}$ that were probably really the earliest observational recording of ocean waves ever made. So the evolving of ocean wave observations has been spanned nearly three centuries. But the pioneer work that Barber (1969) [1] started in 1945 really represented the first major leap forward to advance wave data collection from visual observations to the realm of gage recording that had prevailed throughout the 20th century.

The evolution of wave observation and measurement, however, has not at all been continuous, progressive, or successive. Up to the early 20th century, for two centuries since Marsigli, the science world was still basically relied upon the proficient and accomplished visual observations such as those conducted by Cornish (1934) [4] during his varied oceanographical expeditions in the late 19th and early 20th centuries. Around the same time other means of instrumental explorations for gathering ocean wave information have also started to develop. Among them included a surface wave measuring instrument that was connected to a floating anchor built by William Froude circa 1867 (see Defant, 1961 [5]); and the various efforts in the early years of 20th century on successful usage of stereo photogrammetric pictures for sea surfaces as described in Sverdrup et al. (1941) [6] and Titov (1969) [2]. Those stereo photogrammetric pictures in the early days are, however, merely snap shots of the instant ocean surface obtained after intensive and complicated processing. But they were realistic representations of the ocean surface nevertheless. The height of World War II probably propelled the successful development of the Barber (1969) [1] described pressure wave gage in UK for getting an accurate estimate of wave heights at a given location needed for preparing Normandy landing operation, that conceptual innovation on wave measurement is still being used to this day.

\section{Single Point Wave Measurements-The Inception}

It has been well known that surface waves induce pressure fluctuations over a water column from the surface to the bottom. So it must be an exciting moment, sometime during 1945 in UK, that someone succeeded in constructing an apparatus as described in Barber (1969) [1] in which a bell-shaped metal casting with one side made of thin metal sheet that moved slight inward and outward as the pressure of the water varied when waves passed over and the deflection was detected electrically through 
a cable connecting the apparatus to a shore recording station. That was the beginning of the implementation of a pressure wave gage-and also the beginning of the practical enactment of measuring waves at a single point! Undoubtedly that marked the starting availability of actual wave measurements which also ushered in the unprecedented vigorous decade of postwar international ocean wave research-the decade of 1950's. The available of single point ocean wave data also simultaneously inspired the successful development of subsequent statistical wave data analysis procedures and wave spectrum analysis that has become the mainstream indispensable approach of wave data analysis ever since.

\section{Single Point Wave Measurements- Waxing into the Mainstream Wave Measurement}

Started with the first pressure gage developed in UK for wave measurement during WWII, the in situ, wave measurement has been widely evolved over the later

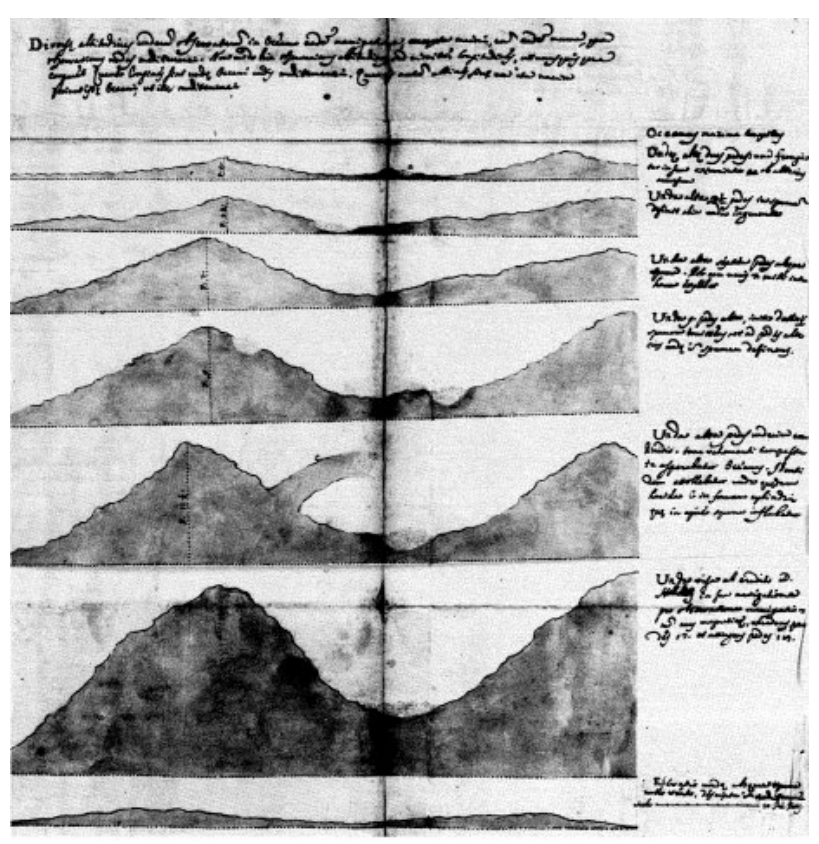

Figure 1. Marsigli’s wave observation plate.

Various heights of waves seen in the ocean during the voyage, except the greatest, named like those we saw in the Mediterranean. We observed not just their heights but also their lengths, so that anyone may find out how much longer the waves in the ocean are than those in the Mediterranean. Few ships are aware of how true this is for the Ocean, in contrast to the Mediterranean.

I. Ocean at its most calm.

. Wave two feet high; one affected at its edge $a$ because of the approach of a higher onc.

3. Wave three and a half feet high. Foam borders another approaching wave.

Wave four feet high without foam. The ship makes seven miles an hour through these.

Wave nine feet high; foam is sent out from the leading face and foam marks the feet of higher waves.

waves.
Wave eleven and a half feet high. In violent storms the ocean then foams. A wave like that at $c$, cylindrical in form and broken into foam at its peak is raised repeatedly.

Wave seen by the learned Dr Halley in his voyage to observe the magnetic needle at sea,

exceeding seventecn feet and reaching eighteen feet.

8. Height of wave without spray, not seen, described in (illegible)

Figure 2. Translations of the texts in Figure 1. years of 20th century to include using other devices such as wave staffs, laser and radar altimeters, buoy accelerometers, sonic and acoustic devices, as well as continued improvements of effective subsurface pressure sensors. Most of these field wave data being collected and utilized, however, are all basically "point observations of threedimensional waves” as pointed out in Dysthe et al. (2008) [7].

The recognition of our conventional wave measurement as "point observations" can be actually traced back as early as Kinsman (1965) [8] who had already rightfully noted in his acclaimed book that it was the intrinsic nature of the prevalent wave measuring system and stated what he saw as the "basic problem":

"The basic problem in measuring waves is that of sampling a time-varying process which is spread out on a two-dimensional surface. Its solution isn't easy. All the methods we have mentioned look only at aspects of the process - time variation at one point of the space, space variation at one instant of time, ... Consequently, what you deduce from the measurements about the process as a whole can be very heavily conditioned by your preconception about the nature of the process". (Bold faced emphasize added).

So essentially for all these years the wave data we collected from the single-point measurement system, which we regard as representative of realistic ocean wave processes, were in fact "heavily conditioned" and localized data that in reality may or may not be the true natural processes of ocean waves.

Of course we do certainly wish that the wave data we measured was not merely a make belief but rather from the true processes of the ocean representing $f(x, y, z, t)$ as it was simplified in practice to be either at a single point, $f\left(x_{0}, y_{0}, z_{0}, t\right)$, or at a single instant, $f\left(x_{0}, y_{0}, z, t_{0}\right)$, as the cases may be. It was clearly an exciting conceptual innovation in 1945 to put in place to replace visual estimation of local waves needed for planning troops landing during the successful Normandy operation. That was clearly also the beginning of modern ocean wind waves study which is still strongly ongoing today. And the single point wave measurements have indeed served us very well and responsible for many of the innovative advancement in ocean wave studies in the second half of the 20th century. But now we are over a decade into the 21st century, it is undeniable that there is in recent years a lacking of true advancements toward enhancing our basic understanding on wind wave processes has set in. Even though the ocean wave studies have been sustained by the theoretical community's continued efforts on propelling more and more feats of higher order nonlinearities that no single point wave measurements can ever 
verify.

One question that no one seems to be interested in asking at the present, is that why would the ocean wave studies community staying quiescent with the conventional conceptualization of single point wave measurement, no more conceptual advancement except to spring up various recording sensors at a single location over the last 50 years while technologies have progressed by leaps and bounds during the same time period? Isn't it time now for more realistic spatial wave measurement for true wave dynamics?

\section{Single Point Wave Measurements- Accomplishment Milestones!}

As we have indicated that the conventional single-point wave measurement has served us quite well. The significant and compelling progresses in technology and computing systems in the last part of 20th century have greatly forged momentous advancements in ocean wave modeling ventures. Note that the development in ocean wave modeling have benefited greatly from the many empirical headways, mainly in the formulation of a wave spectrum, as resulted from analysis of the available single point wave measurements:

- 1958 Phillips Equilibrium Range (Phillips) [9];

- 1961 Kitaigorodskii Similarity Theory (Kitaigorodskii) [10];

- 1964 Pierson-Moskowitz Spectrum (Pierson and Moskowitz) [11];

- 1973 JONSWAP Spectrum (Hasselmann et al.) [12];

- WAM model (Komen et al., 1994) [13].

This brief list only pertains to the notion that they are resulted from single point wave measurements, so it is by no means a complete list of ocean wave's research accomplishments in 20th century. The starting of the first established milestone item with Phillips' 1958 work is basically a personal choice. Understandably there had already been nearly two decades of vigorous ocean wave's research in US and Europe before that. But the equilibrium range is clearly an early conceptual triumph that became an inspirational guiding light toward later wave spectrum formulations, along with the subsequent accomplishments that eventually led to the modern fruition in ocean wave modeling.

\section{Single Point Wave Measurements- Stagnation Unfettered}

With the prevalent single-point wave measurements providing basic wave data over the decades leading to the new century. Undeniably we are still not able to yet grow beyond a couple of 1950's conjectures of how wind waves are generated. The primary hindrance seems to hinged on the fact that after all these years, with all the single point wave measurements being collected around the world, we really do not know much more about wind generated waves in the ocean than we have already knew decades ago. So ever since the WAM model (Komen el al., 1994) [13] was developed, most of the efforts in the ocean waves community have been toward resorting into delving for further higher order nonlinearities with the expectation of improving accuracy. In the mean time, however, the single point wave measurements are certainly not capable of providing viable information with higher nonlinearities. So we have basically been in a period of stagnation doing further and further refinements and hoping for better and better accuracy that no single point wave measurement can provide. What we need now is a break from single point wave measurement to make further breakthrough possible!

\section{Single Point Wave Measurements-What Exactly Do They Represent in the First Place?}

Since conventionally waves are measured from single point wave sensors, what have they measured is naturally the sea surface fluctuations at a single point. With ocean waves being a dynamical process, it is questionable that single point measurement will able to reflect the dynamical nature of the ocean waves. So it all boils down to objective, hopefully, but subjectively in reality, interpretations of the data recorded-which is what Kinsman (1965) [8] described as "very heavily conditioned by your preconception about the nature of the process." As we have alluded Dysthe et al.'s (2008) [7] characterization that the data are "point observations of three-dimensional waves". Clearly single point measurements are by no means of three-dimensional waves. What, then, do they really represent?

Here's a personal observation that no one had ever discussed before: Imagine ocean waves in the world of "Flatland"-a fictional two-dimensional world created by 19th century English scholar Edwin Abbott (18381926). Of course Mr. Abbott did not indicate if there's ocean in the Flatland, but we can surmise that there must be ocean surrounds the Flatland and so there must be ocean waves also. And the smart people of the Flatland must be able to develop instrumentations to measure ocean waves on the Flatland. Now what might be a measured ocean wave record in the Flatland look like? Without any stretch of imagination, it will be look exactly like the single point measurement in our three dimensional world!

So it should not be surprising that our single point ocean wave measurements are in fact appropriate to the Flatland waves. In other words, all the wave measurements and wave studies we have done throughout the 20th century and up to now have been basically for the 
Flatland rather than the 3D world we are living in. In order to truly measure wave dynamics in our three-dimensional world, we need more than single point wave measurement—we need spatial wave measurement!

\section{An Overlooked Gem of an Early 21st Century Innovation}

The wheel of progress turns slowly, but it has never ceased turning! There's a paper published eight years ago seems to be holding tremendous potential. Warnek and Wu (2006) [14] developed a spatial wave measurement system, the Automated Trinocular Steoro Imaging System (ATSIS), shown in Figure 3, to use widely available digital video cameras to make non-intrusive measurement of temporal evolution of three-dimensional wave characteristics. The ATSIS system leaps forward from conventional single point wave measurement into a whole new world of realistically dynamical, spatial wave measurement, an instant segment of the measurement is shown in Figure 4. Instead of verbal description, one has to see an actual result in order to comprehend the significance of this new system a true spatial $f(x, y, z, t)$ measurement. A five seconds recording can be seen online at http://www.youtube.com/watch?v=pMYENsrSLN4. Like the first time a pressure gage brought the wave observation into the middle of 20th century. The ATSIS would certainly lift the wave studies in stagnation into the vibrant 21st century. The only difference seems that the pressure gage was an instant acceptance by the community. This new ATSIS system, however, has not yet received a wide recognition it deserves. Mostly because the ocean wave research world, that has been conditioned to be complacent on single point measurement for so many decades, is really unprepared for such a rigorous system. An attempt on preliminary analysis of the new ATSIS data is given in Liu, et al. (2009) [15].

Of course, while Wanek and Wu (2006) [14] may be

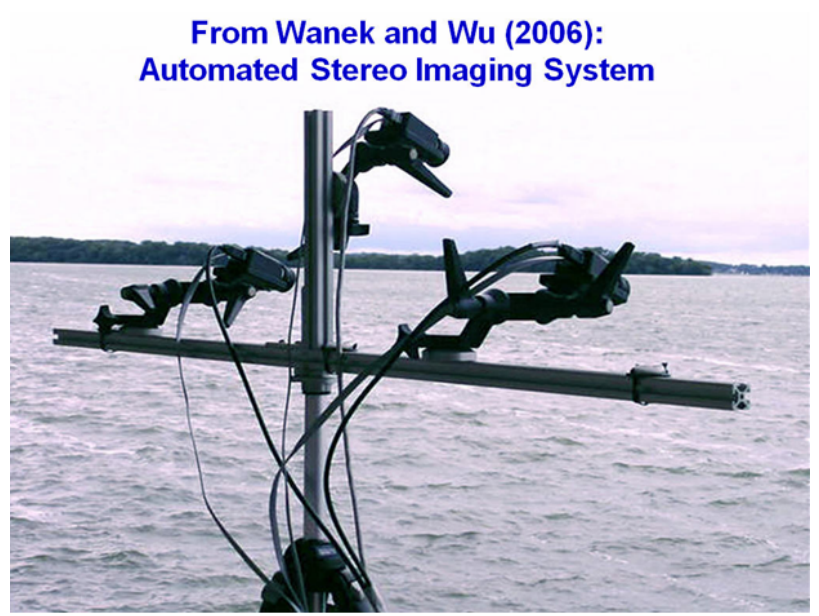

Figure 3. The ATSIS.

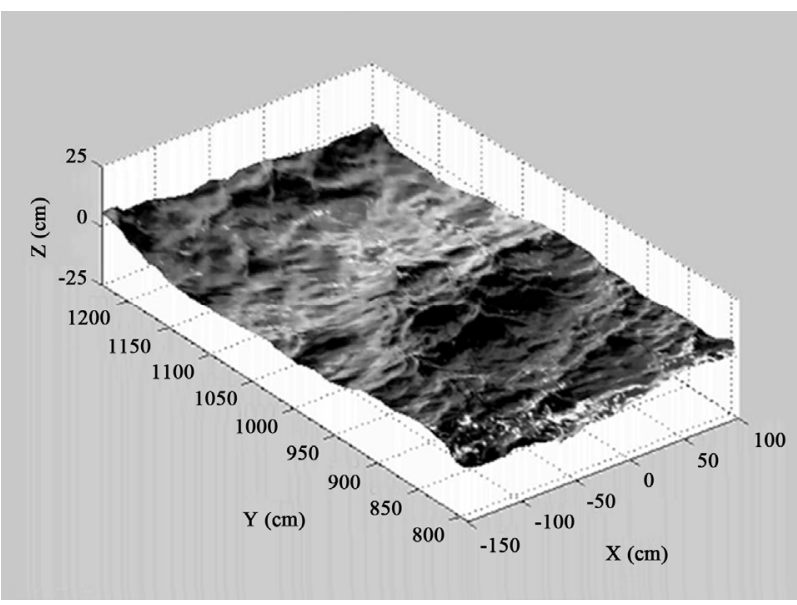

Figure 4. An instant segment of ATSIS spatial waves measurement.

the early pioneers of making practical stereo spatial wind wave measurements, they are by no means the only one. A number of similar efforts have been appeared in the literatures since then, though none seem to indicate an awareness of Wanek and Wu's work or have gone as successful on providing 3D wave data yet. It is nevertheless gratifying to see that efforts have started to spring forward to finally move beyond the conventional single point wave measurement system. One recent admirable and comprehensive publication by Benetazzo (2012) [16], among others, has especially captured the spirit of what ocean wind wave measurement and research in the 21st century should aimed at achieving.

\section{Concluding Remarks}

The editorial of the 2012 New Year issue of the New Scientist magazine has a thoughtful byline that says:

"Next year let's deal with the world as it is, not as we would like it to be".

I think this thought can be appropriately applied to the wind wave researches also. For too long we have been worked on a strictly prescribed academic ocean, e.g. an ocean with its surface fluctuations follow Gaussian random process and ocean wave heights follow Rayleigh distribution, and all the measurement has to be of the order of 20 minutes - not too long so that it will not be losing stationarity and not too short then the data will be unstable. And all the theory and model verifications have to be all based on the prescribed measurements of the well behaved ocean. Reality relevant to the real ocean out there seems to be of less concern. Can the conventional main stream ocean wave research establishment be persuaded on dealing with the real ocean waves for a change, not the strictly prescribed one we have been complacently working within that have led us to our present stagnation stage? Well, the future is unlimited! 


\section{Acknowledgements}

Discussions with Luigi Cavaleri, Dave Schwab, and Chin Wu over the years have been major source of stimulation and inspirations. GLERL Contribution No. 1645.

\section{REFERENCES}

[1] N. F. Barber, "Water Waves,” Wykeham Publications, London, 1969.

[2] L. F. Titov, "Wind-Driven Waves," Gidrometeorologicheskoe Izdatelstvo, Leningrad, 1969.

[3] A. McConnel, "L. F. Marsigli's Voyage to London and Holland, 1721-1722," Notes and Records of the Royal Society, Vol. 41, No. 1, 1986, pp. 39-76. doi:10.1098/rsnr.1986.0003

[4] V. Cornish, "Ocean Waves and Kindred Geophysical Phenomena,” Cambridge University Press, 1934.

[5] A. Defant, "Physical Oceanography," Pergamon Press, Oxford, 1961.

[6] H. U. Sverdrup, M. W. Johnson and R. H. Fleming, "The Oceans, Their Physics, Chemistry, and General Biology,” Printice-Hall, 1942.

[7] K. Dysthe, H. E. Krogstad and P. Muller, "Oceanic Rogue Waves,” Annual Review of Fluid Mechanics, Vol. 40, 2008, pp. 287-310.

doi:10.1146/annurev.fluid.40.111406.102203

[8] B. Kinsman, "Wind Waves Their Generation and Propagation on the Ocean Surface,” Printice Hall, 1965.

[9] O. M. Phillips, "The Equilibrium Range in the Sprvtrum of Wind-Generaytyed Water Waves," Journal of Fluid Mechanics, Vol. 4, No. 4, 1958, pp. 426-434.
doi:10.1017/S0022112058000550

[10] S. A. Kitaigoroodskii, "Application of the Theory of Similarity to the Analysis of Wind Generated Wave Motion as a Stochastic Process,” Izvestiya Geophysical. Services, Vol. 1, 1962, pp. 105-117.

[11] W. J. Pierson Jr. and L. Moskowitz, “A Proposed Spectral Form for Fully Developed Wind Seas Based on the Similarity Theory of S. A. Kitaigorodskii,” Journal of Geophysical Research, Vol. 69, No. 24, 1964, pp. 5181-5190. doi:10.1029/JZ069i024p05181

[12] K. Hasselmann, T. P. Barnett, E. Bouws, H. Carlson, D. E. Cartwright, K. Enke, J. A. Ewing, H. Gienapp, D. E. Hasselmann, P. Kruseman, A. Meerburg, P. Muller, D. J. Olbers, K. Richter, W. Sell and H. Walden, "Measurement of Wind-Wave Growth and Swell Decay during the Joint North Sea Wave Project (JONSWAP),” Suppl. A, Deutches Hydrographisches Institut, 1973.

[13] G. J. Komen, L. Cavaleri, M. Donelan, K. Hasselmann, S. Hasselmann and P. A. E. M. Janssen, "Dynamics and Modelling of Ocean Waves,” Cambridge University Press, Cambridge, 1994. doi:10.1017/CBO9780511628955

[14] J. W. Wanek and C. H. Wu, “Automated Trinocular Stereo Imaging System for Three-Dimensional Surface Wave Measurement," Ocean Engineering, Vol. 33, No. 5-6, 2006, pp. 723-747. doi:10.1016/j.oceaneng.2005.05.006

[15] P. C. Liu, C. H. Wu, K. R. MacHutchon and D. J. Schwab, "An Analysis of Measurement from a 3D Oceanic Wave Field,” In Brebbia, Benassai and Rodriguez, Eds., Coastal Processes, WIT Press, 2009.

[16] A. Benetazzo, F. Fedele, G. Gallego, P.-C. Shih and A. Yezzi, "Offshore Stereo Measurements of Gravity Waves," Coastal Engineering, Vol. 64, 2012, pp. 127-138. doi:10.1016/j.coastaleng.2012.01.007 